\title{
PENGARUH SERAT BAJA (DRAMIX) TERHADAP KUAT LENTUR PADA ROLLER COMPACTED CONCRETE (RCC)
}

\author{
Adita Dwi Sampurno', Iman Satyarno², Agus Taufik Mulyono ${ }^{3}$ \\ ${ }^{1}$ Magister Sistem dan Teknik Transportasi UGM; \\ ${ }^{2,3}$ Departemen Teknik Sipil dan Lingkungan UGM \\ Email: adita.dwi.sampurno@gmail.com
}

\begin{abstract}
Rigid pavement for highways in Indonesia started as an alternative for road pavement. Roller compacted concrete $(R C C)$ is one type of dry concrete mixture with low water cement ratio (slump $<5 \mathrm{~cm}$ ). The $R C C$ spreading is the same as the asphalt concrete pavement that uses the finisher and is compacted using a roller. This research uses RCC mix design with cement water factor value 0,25. Additional silicafume materials of $10 \%$, superplasticizer $2.4 \%$, and steel fiber (dramix) with variations of $0.5 \%$ and $1 \%$. RCC Compaction using standard proctor tools. Testing of bending forces and compression of concrete in 1 day and 28 days. The result of research of RCC variation of $0.5 \%$ steel fiber and 1 day old concrete obtained Flexural Strength of 4,2 MPa while 28 days concrete gained Flexural Strength of 5,7 MPa. The variation of $1 \%$ steel fiber 1 day concrete obtained 3.4 MPa Flexural Strength, while the 28 days concrete obtained 6.1 MPa Flexural Strength.
\end{abstract}

Keywords: Roller Compacted Concrete (RCC), Steel Fiber (dramix), Flexural Strength

\begin{abstract}
ABSTRAK
Perkerasan kaku di Indonesia semakin banyak digunakan sebagai alternatif perkerasan jalan raya. Roller Compacted Concrete (RCC) atau beton padat giling (BPG) merupakan salah satu jenis campuran beton kering dengan faktor air semen (FAS) yang rendah (slump <5 cm). Penghamparan RCC sama seperti penghamparan perkerasan beton aspal yang menggunakan finisher dan dipadatkan menggunakan roller. Kajian ini menggunakan mix design RCC dengan nilai faktor air semen 0,25. Bahan tambah silicafume sebesar 10\%, superplasticizer 2,4\%, dan serat baja (dramix) dengan variasi $0,5 \%$ dan $1 \%$. Pemadatan RCC menggunakan alat standar proctor. Pengujian kuat lentur pada beton umur 1 hari dan 28 hari. Hasil kajian RCC variasi serat baja 0,5\% beton umur 1 hari diperoleh kuat lentur 4,2 MPa, sedangkan beton umur 28 hari diperoleh kuat lentur 5,7 MPa. Variasi serat baja $1 \%$ beton umur 1 hari diperoleh kuat lentur 3,4 MPa, sedangkan beton umur 28 hari diperoleh kuat lentur 6,1 MPa.
\end{abstract}

Kata kunci: Roller Compacted Concrete (RCC), Beton Padat Giling (BPG), Serat baja (dramix), Kuat lentur 


\section{PENDAHULUAN}

Penyediaan sarana dan prasarana transportasi merupakan salah satu faktor penting yang dapat mendorong kegiatan perekonomian nasional dan daerah. Prasarana tersebut utamanya adalah jalan raya yang merupakan salah satu sub komponen sistem transportasi yang paling dominan dan sering digunakan. Saat ini, arus lalu lintas darat menggunakan jalan raya masih menjadi arus lalu lintas utama dalam pendistribusian barang komoditi ekonomi antar wilayah maupun pergerakan manusia dalam aktivitasnya. Jalan raya berperan menjadi penghubung antar pusat aktivitas yang memungkinkan masyarakat dapat mengakses berbagai kebutuhan pemenuhan fasilitas, serta menjadi syarat penting untuk masuknya investasi ke dalam sebuah wilayah. Jalan raya memiliki fungsi sebagai prasarana vital dalam suatu wilayah tersebut, maka penyediaan jalan raya harus diperhatikan mulai dari perencanaan struktur perkerasan yang kuat dan tahan lama agar segala aktivitas di atasnya dapat berjalan lancar, cepat, dan nyaman.

Perkerasan jalan raya di Indonesia pada umumnya masih berupa perkerasan lentur (flexible pavement), sedangkan perkerasan kaku (rigid pavement) hanya sebagian kecil. Perkerasan lentur (flexible pavement) adalah perkerasan jalan yang menggunakan aspal sebagai bahan pengikat material pasir dan split, sedangkan perkerasan kaku adalah perkerasan jalan yang menggunakan bahan pengikat dari semen sebagai struktur utama dan lapis aus permukaan, yang kemudian dikenal dengan perkerasan kaku beton semen (rigid pavement). Jenis perkerasan jalan ini mempunyai karakteristik yang berbeda-beda. Penggunaan perkerasan kaku semakin banyak dengan berbagai pertimbangan dari segi kelebihannya guna menunjang pertumbuhan ekonomi (Pratama, 2018).

Penggunaan beton pada konstruksi perkerasan jalan mempunyai beberapa kelebihan dibandingkan menggunakan perkerasan aspal, yaitu kuat tekan beton yang sangat tinggi dan keawetan yang lebih baik. Selain itu, perkerasan beton lebih tahan terhadap cuaca panas dan lebih tahan terhadap pengaruh air. Melihat berbagai keunggulan tersebut, maka konstruksi perkerasan beton semakin banyak menggantikan perkerasan aspal pada ruas jalan dengan beban lalu lintas tinggi. Perkerasan beton menjadi pilihan alternatif guna menciptakan konstruksi perkerasan jalan dengan performa tinggi sekaligus tahan lama. Perkerasan beton dapat berupa beton normal atau beton padat giling (roller compacted concrete).

Perkerasan beton memiliki kelemahan yaitu terhadap gaya tarik dan plastic shrinkage yang menyebabkan retak pada beton, sehingga memperpendek umur beton. Hal tersebut menjadikan adanya biaya lebih untuk melakukan perbaikan jalan beton, dimana dampak lain yang juga ditimbulkan adalah terhambatnya lalu lintas karena proses pembangunan jalan beton memerlukan waktu cukup lama. Inovasi pada campuran beton sangat dibutuhkan agar kualitas semakin bermutu dan mengurangi sifat kelemahan beton. Beton normal diperoleh dengan cara mencampurkan semen portland, air, dan agregat. Adapun untuk jenis beton khusus (selain beton normal) ditambahkan bahan tambah, misalnya pozolan, bahan kimia pembantu, serat, dan sebagainya. Tujuan pemberian bahan tambah ialah untuk menghasilkan beton khusus yang lebih baik daripada beton normal (Tjokrodimuljo, 2007).

Roller Compacted Concrete (RCC) atau beton padat giling (BPG) merupakan salah satu jenis campuran beton dengan nilai slump nol atau campuran beton sedikit kering dengan faktor air semen (FAS) yang rendah. Bahan penyusun RCC relatif sama dengan beton normal yaitu semen, agregat halus (pasir), agregat kasar (batu pecah), dan air. Proses penghamparan sama dengan penghamparan beton aspal, yaitu menggunakan finisher kemudian dipadatkan menggunakan roller. Kelebihan utama dari RCC adalah meminimalisir 
diversi/overtopping penyebab keretakan jalan serta menekan biaya pembangunan dan mempersingkat waktu pelaksanaan. Upaya tersebut dilakukan untuk menghasilkan perkerasan RCC agar umur pakai perkerasan lebih lama perlu didesain dengan beton bermutu tinggi (Saragi, 2014).

Roller Compacted Concrete (RCC) atau beton padat giling (BPG) merupakan salah satu jenis campuran beton dengan nilai slump nol atau campuran beton kental dengan faktor air semen (FAS) yang rendah. Bahan penyusun $R C C$ relatif sama dengan beton normal yaitu semen, agregat halus (pasir), agregat kasar (batu pecah), dan air. Proses penghamparan sama dengan penghamparan beton aspal, yaitu menggunakan finisher kemudian dipadatkan menggunakan roller. Kelebihan utama dari $R C C$ adalah meminimalisir diversi/overtopping penyebab keretakan jalan serta menekan biaya pembangunan dan mempersingkat waktu pelaksanaan. Upaya yang dilakukan untuk menghasilkan jalan dengan perkerasan $R C C$ yang lebih kuat, ulet, dan mempunyai umur pakai lebih lama perlu didesain dengan beton bermutu tinggi.

Ditjen Bina Marga (2006) dalam Lapis Pondasi Beton Padat Giling (BPG/RCC) menyatakan lapis pondasi beton padat giling (BPG) atau Roller Compacted Concrete $(R C C)$ adalah salah satu jenis lapis pondasi agregat yang distabilisasi dengan semen disamping lapis pondasi agregat semen (LPAS) dan lapis pondasi bawah agregat semen (LPBAS). Lapis pondasi beton padat giling (BPG) adalah campuran agregat, semen, dan air yang kental atau "slump nol", disamping itu memiliki gradasi agregat campuran yang khusus atau tidak sama dengan gradasi campuran untuk LPAS ataupun LPBAS.

Berdasarkan ACI 207.5R-89, dalam saragi, (2014) Roller Compacted Concrete (RCC) adalah beton yang dipadatkan dengan memakai alat pemadat roller. Kondisi campuran beton segar saat pemadatan haruslah mampu menahan berat alat pemadatan roller. RCC memiliki bahan dasar yang sama seperti beton normal seperti semen, air, agregat. Perbedaan RCC dengan beton biasa terletak pada konsistensi adukan. Campuran beton harus cukup kering untuk mencegah alat pemadat tenggelam agar konsolidasi menjadi efektif, tetapi juga harus cukup basah agar mortar terdistribusi merata selama pengadukan dan pemadatan. RCC untuk perkerasan jalan termasuk kedalam jenis perkerasan kaku (rigid). Perbedaan dengan beton normal yaitu tanpa menggunakan joint, dowel, tie bar, atau baja tulangan. Pemadatan RCC menggunakan roller sebagai pemadat dengan nilai slump nol.

Penggunaan RCC di Indonesia mulai banyak diteliti sebagai perkerasan alternatif dengan pertimbangan berbagai kelebihan yang diperoleh dibandingkan menggunakan beton normal. Penerapan RCC diharapkan mampu menahan beban lalu lintas yang melebihi kapasitas daya dukung perkerasan serta minim kerusakan pada daerah dengan curah hujan tinggi daripada perkerasan lentur yang mudah rusak apabila menerima beban berlebih serta terlalu sering terendam air. Pertimbangan tersebut dirasa cukup untuk menggunakan beton RCC sebagai alternatif perkerasan jalan.

Bahan penysun RCC relatif sama dengan beton normal yaitu semen, agregat halus (pasir), agregat kasar (batu pecah), dan air. Proses pencampuran sama dengan pekerjaan beton normal, tetapi penghamparannya yang berbeda yaitu menggunakan finisher dengan pemadat roller.

Zai, dkk (2014) menyatakan bahwa untuk mengurangi porositas semen dapat digunakan bahan tambah yang bersifat mineral (additive) yang lebih banyak bersifat penyemenan dan banyak digunakanuntuk memperbaiki kinerja kekuatan beton, terutama untuk beton mutu tinggi. Salah satu additive tersebut adalah silica fume. Silica fume adalah material pozollan yang sangat halus, dengan kadar kandungan senyawa $\mathrm{SiO} 2$ yang sangat tinggi (> 90\%) danmemiliki ukuran sekitar $1 / 100$ ukuran rata-rata partikel semen. 
Muzamil dan Budiono (1994) dalam penelitiannya mengatakan bahwa penggunaan bahan tambah superplasticizer dapat mengurangi faktor airsemen (fas) dan menambah workability tetapi akan memperlambat proses pengeringan apabila penambahan yang dilakukan dalam jumlah besar. Penambahan optimal dicapai pada konsentrasi sebesar $1 \%$ dari berat adukan semen.

Beton serat (fibre concrete) adalah bahan komposit yang terdiri dari beton biasa dan bahan lain yang berupa serat. Serat umumnya berupa batang-batang dengan diameter antara 0,005 sampai $0,5 \mathrm{~mm}$ dan panjang sekitar $25 \mathrm{~mm}$ sampai $100 \mathrm{~mm}$ (Tjokrodimuljo, 2007).

Briggs (1974) meneliti fiber beraspek rasio tinggi $(\mathrm{l} / \mathrm{d}>100)$ akan menyebabkan fiber menggumpal bersama-sama sehingga sangat sulit disebarkan secara merata di dalam adukan, sedang untuk fiber beraspek rasio rendah $(\mathrm{l} / \mathrm{d}<50)$ tidak akan terjadi ikatan yang baik dengan betonnya.

Penambahan serat pada beton memperbesar kemampuan beton menyerap energi lenturan, konsentrasi serat yang optimal adalah $1 \%$ volume adukan, penambahan serat akan menurunkan kelecakan adukan secara cepat. Nilai indeks tahanan lentur dipengaruhi oleh umur beton sehingga penggunaan dibawah umur 28 hari untuk perancangan struktur akan memperkecil angka keamanan (Sudarmoko, 1993).

Serat baja yang digunakan berupa serat baja merk dramix dengan tipe 3D panjang (l) $35 \mathrm{~mm}$, diameter (d) 0,55 mm, dan aspek rasio (I/d) 65. Pemilihan tipe serat baja 3D sesuai keterangan pada brosur untuk konstruksi lantai.

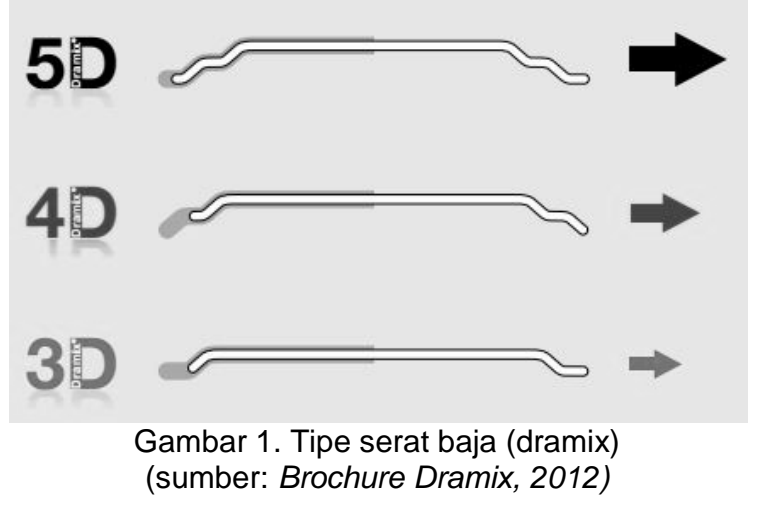

Kajian ini bertujuan untuk mengetahui pengaruh penggunaan bahan tambah silica fume, superplasticizer, dan serat baja (dramix) pada roller compacted concrete
(RCC) dengan nilai faktor air semen rendah serta pengaruh terhadap kuat lentur beton.

\section{METODE}

Tahapan kajian dimulai dari pengumpulan literatur sebagai landasan teori dan studi pustaka. Peralatan dan bahan dipersiapkan berdasarkan perhitungan kebutuhan material. Pengujian material agregat kasar dan agregat halus untuk mengetahui sifat bahan. Penyusunan rancangan campuran (mix design), penambahan silica fume, penggunaan superplasticizer, serta penambahan serat baja (dramix). Pengujian vebe time dan slump pada campuran beton serta mencetak benda uji berbentuk balok. Perawatan benda uji hingga waktu pengujian beton umur 1 hari dan 28 hari. 
Tahap selanjutnya menganalisis hasil pengujian serta menarik kesimpulan kajian.

Kajian ini dilakukan di Laboratorium Bahan Bangunan, Departemen Teknik Sipil dan Lingkungan, Fakultas Teknik, Universitas Gadjah Mada, Yogyakarta.

Bahan-bahan yang digunakan diantaranya adalah:

1. Semen jenis PCC dengan merk dagang Semen tiga roda.

2. Agregat kasar berupa batu pecah dengan ukuran maksimal $20 \mathrm{~mm}$ yang berasal dari Clereng, Kabupaten Kulonprogo, Yogyakarta.

3. Agregat halus (pasir) yang digunakan berasal dari Cangkringan, Kabupaten Sleman, Yogyakarta.

4. Silica fume dari PT. Sika Indonesia.

5. Super plasticizer (SP) dari PT. Sika Indonesia.

6. Serat baja (dramix) dari Bekaert.

Pengujian bahan agregat kasar dan agregat halus yang dilakukan antara lain:

1. Pengujian berat jenis

2. Pengujian berat satuan

3. Pengujian gradasi

4. Pengujian kadar lumpur

5. Pengujian los angeles dan rudeloff (agregat kasar)

6. Pengujian kandungan zat organik (agregat halus)

Mix design roller compacted concrete (RCC) menggunakan Tata Cara Pembuatan Rencana Campuran Beton Normal SNI 03-2834-2000. Penentuan Benda uji beton yang digunakan berbentuk balok dengan ukuran $150 \mathrm{~mm} \times 150 \mathrm{~mm} \times$ $600 \mathrm{~m}$ sebanyak 12 buah. Pemadatan benda uji menggunakan alat standard proctor dengan jumlah tumbukan 279 setiap lapis (dibagi 3 lapis).

Kuat lentur merupakan suatu sifat yang sangat penting untuk menahan retak, terutama yang diakibatkan oleh pemuaian akibat peningkatan temperatur. Kuat lentur beton hanya berkisar 9-15\% dari kuat tekannya, sehingga dalam perancangan kuat lentur beton dianggap nol. Beberapa penelitian terdahulu menunjukkan bahwa penambahan fiber pada adukan beton akan meningkatkan kuat lentur beton sehingga mampu menahan retak yang terjadi akibat adanya tegangan lentur (Dipohusodo, 1994).

Pengujian kuat lentur menggunakan metode dua titik pembebanan sesuai dengan SNI 4431:2011. Pengujian dilakukan pada beton umur 1 hari dan 28 hari.Persamaan yang digunakan untuk menghitung kuat lentur dengan persamaan 1.

$\sigma=\frac{P \cdot L}{b \cdot h^{2}}$

dengan:

$\sigma=$ kuat lentur (MPa)

$\mathrm{P}=\operatorname{beban}(\mathrm{N})$

$\mathrm{L}=$ jarak antara perletakan $(\mathrm{mm})$

$\mathrm{b}=$ lebar tampak balok (mm)

$\mathrm{h}=$ tinggi tampak balok $(\mathrm{mm})$

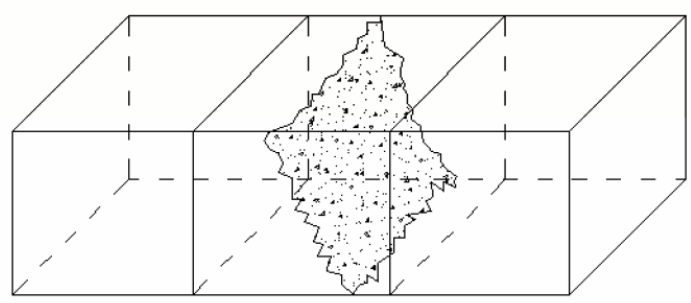

Gambar 2. Patah pada 1/3 bentang tengah (Sumber: SNI 4431:2011)

Pengujian untuk bidang patah berada diluar daerah pusat (daerah 1/3 jarak titik perletakan bagian tengah) serta jarakantara titik pusat dan titik patah kurang dari $5 \%$ dari jarak titik antara perletakan. Perhitungan kuat lentur menggunakan persamaan 2 . 


$$
\sigma=\frac{\text { P.a }}{\text { b.h }}
$$

dengan:

$$
\begin{aligned}
\sigma \quad= & \text { Kuat lentur benda uji (MPa) } \\
\mathrm{P} \quad & \text { Beban tertinggi yang terbaca } \\
& \text { pada mesin uji (N) } \\
\mathrm{L} \quad & \text { Jarak bentang antara dua garis } \\
& \text { perletakan (mm) } \\
\mathrm{b} \quad= & \text { Lebar tampang lintang patah } \\
& \text { arah horizontal (mm) } \\
\mathrm{h} \quad & \text { Lebar tampang lintang patah } \\
& \text { arah vertikal (mm) } \\
\mathrm{a} \quad & \text { Jarak rata-rata antara tampang } \\
& \text { lintang patah dan tumpuan luar } \\
& \text { yang terdekat, diukur pada } 4 \\
& \text { tempat pada sudut dari bentang }
\end{aligned}
$$

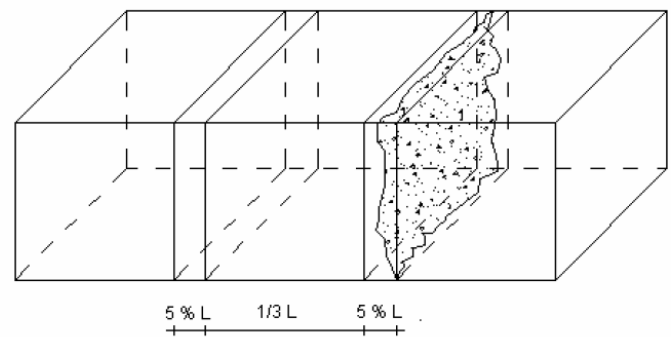

Gambar 3. Patah di luar $1 / 3$ bentang tengah dan < $5 \%$ dari bentang

(Sumber: SNI 4431:2011)

Benda uji yang mengalami patah diluar pusat (daerah 1/3 jarak titik perletakan bagian tengah) serta jarak antara titik pusat dan titik patah kurang dari $5 \%$ dari jarak titik antara perletakan maka hasil pengujian tersebut tidak dapat digunakan. Benda uji beton tidak dapat menggambarkan kekuatan beton karena posisi patah berada dekat dengan tumpuan/perletakan bukan pada posisi gaya yang diberikan.

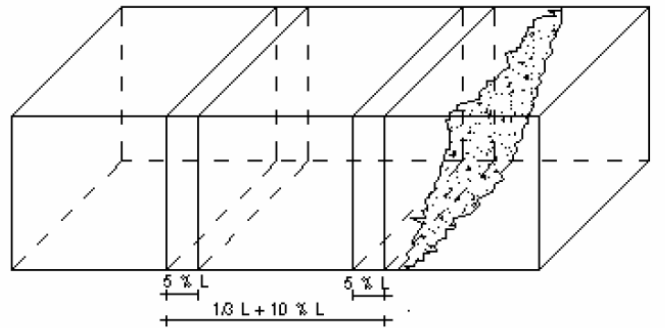

Gambar 4. Patah di luar $1 / 3$ bentang tengah dan > $5 \%$ dari bentang (Sumber: SNI 4431:2011)
Tahapan kajian dimulai dari pengumpulan literatur sebagai landasan teori dan studi pustaka. Peralatan dan bahan dipersiapkan berdasarkan perhitungan kebutuhan material. Pengujian material agregat kasar dan agregat halus untuk mengetahui sifat bahan.

Campuran beton harus memperhatikan komposisi bahan penyusun beton yang digunakan. Syarat bahan juga harus memenuhi persyaratan karena sangat menentukan mutu yang akan dihasilkan. Beberapa hal yang harus diperhatikan:

1. Variasi nilai FAS 0,25.

2. Replace semen sebesar $10 \%$ dengan silica fume.

\begin{tabular}{|c|c|c|}
\hline Jenis Benda Uji & Umur Beton & Balok \\
\hline Dramix & 1 Hari & 3 \\
\hline $0,5 \%$ & 28 Hari & 3 \\
\hline Dosis Dramix 1 & 1 Hari & 3 \\
\hline$\%$ & 28 Hari & 3 \\
\hline
\end{tabular}

3. Penambahan superplasticizer sampai $2,4 \%$.

4. Penambahan serat baja (dramix) sebesar $0,5 \%$ dan $1 \%$ dari volume campuran (berat jenis serat baja 7800 $\left.\mathrm{kg} / \mathrm{m}^{3}\right)$.

Penentuan Benda uji beton yang digunakan berbentuk balok dengan ukuran $150 \mathrm{~mm} \times 150 \mathrm{~mm} \times 600 \mathrm{~mm}$ sebanyak 12 buah. Pemadatan benda uji menggunakan pemukul standard proctor dengan berat 2,5 kg yang dijatuhkan dari ketinggian $30,5 \mathrm{~cm}$.

Tabel 1. Jumlah benda uji

Persiapan bahan semen, air, agregat kasar, agregat halus yang dibutuhkan sesuai dengan hasil perhitungan mix design dengan bahan tambah serat baja untuk variasi $0,5 \%$ dan $1 \%$. Kadar bahan tambah super plasticizer menggunakan nilai $2,5 \%$, sedangkan bahan tambah mineral silica fume mengganti sebagian komposisi semen sebesar $10 \%$. Pengujian 
slump dilakukan setelah pencampuran dengan nilai kurang dari $5 \mathrm{~cm}$ sebagai syarat beton kering.

Pengujian lainnya menggunakan uji vebe time untuk mengetahui kemudahan

\section{HASIL DAN PEMBAHASAN}

Pengujian agregat kasar dan agregat halus sesuai standar pemeriksaan pada spesifikasi perkerasan beton semen Bina Marga 2010 revisi 3.

$\underline{\text { Tabel 2. Hasil pengujian agregat kasar }}$

\begin{tabular}{clc}
\hline No & \multicolumn{1}{c}{ Pengujian } & Hasil \\
\hline 1 & Berat jenis (SSD) & 2,66 \\
2 & Berat satuan (padat) & $1565 \mathrm{~kg} / \mathrm{m}^{3}$ \\
3 & Kadar lumpur & $0,78 \%$ \\
4 & Analisa saringan & maks. $20 \mathrm{~mm}$ \\
5 & Kadar air & $2,34 \%$ \\
6 & Rudeloff & $11,40 \%$ \\
7 & Los Angles (uji & $20,44 \%$ \\
& abrasi) & \\
\hline
\end{tabular}

Tabel 3. Hasil pengujian agregat halus

\begin{tabular}{|c|c|c|}
\hline No & Pengujian & Hasil \\
\hline 1 & Berat jenis (SSD) & 2,74 \\
\hline 2 & Kadar organik & $\begin{array}{l}\text { lebih muda dari } \\
\text { warna standar }\end{array}$ \\
\hline 3 & Berat satuan (padat) & $1726 \mathrm{~kg} / \mathrm{m}^{3}$ \\
\hline 4 & Kadar lumpur & $3,30 \%$ \\
\hline 5 & Kadar air & $1,83 \%$ \\
\hline 6 & Analisa saringan & zona 2 \\
\hline
\end{tabular}

Kebutuhan material campuran (mix design) roller compacted concrete untuk nilai fas 0,25 dengan bahan tambah silica fume sebesar $10 \%$ (subtitusi semen) dan superplasticizer $2,4 \%$. Perbandingan berat agregat kasar dengan agregat halus yaitu $55 \%$ : 45\%. Kebutuhan serat baja (dramix) untuk variasi $0,5 \%$ sebesar $39 \mathrm{~kg} / \mathrm{m}^{3}$ dan variasi $1 \%$ sebesar $78 \mathrm{~kg} / \mathrm{m}^{3}$.

Tabel 4. Mix design RCC $1 \mathrm{~m}^{3}$

\begin{tabular}{|c|c|c|c|}
\hline No & Material & Berat & Satuan \\
\hline 1 & $\begin{array}{l}\text { Semen yang } \\
\text { digunakan }\end{array}$ & 423 & $\mathrm{~kg}$ \\
\hline 2 & Air yang digunakan & 118 & $\mathrm{~kg}$ \\
\hline 3 & Agregat kasar & 1.068 & $\mathrm{~kg}$ \\
\hline 4 & Agregat halus & 874 & $\mathrm{~kg}$ \\
\hline 5 & Silica fume & 47 & $\mathrm{~kg}$ \\
\hline 6 & Superplasticizer & 10 & $\mathrm{~kg}$ \\
\hline
\end{tabular}

pelaksanaan (workability) lebih dari 12 detik yang menandakan kelecakan beton rendah. Perawatan benda uji hingga waktu pengujian beton umur 1 hari dan 28 hari. Tahap selanjutnya menganalisis hasil pengujian serta menarik kesimpulan.

Hasil pengujian vebe time dan slump dalam kajian ini untuk masing-masing variasi serat baja.

Tabel 5. Hasil pengujian vebe time dan slump

\begin{tabular}{clcc}
\hline No & \multicolumn{1}{c}{ Pengujian } & $\begin{array}{c}\text { Variasi } \\
0,5 \%\end{array}$ & $\begin{array}{c}\text { Variasi } \\
1 \%\end{array}$ \\
\hline 1 & $\begin{array}{l}\text { Pengujian slump } \\
\text { (cm) }\end{array}$ & 0 & 0 \\
2 & $\begin{array}{l}\text { Pengujian vebe time } \\
\text { (detik) }\end{array}$ & 34,6 & 41,8 \\
\hline
\end{tabular}

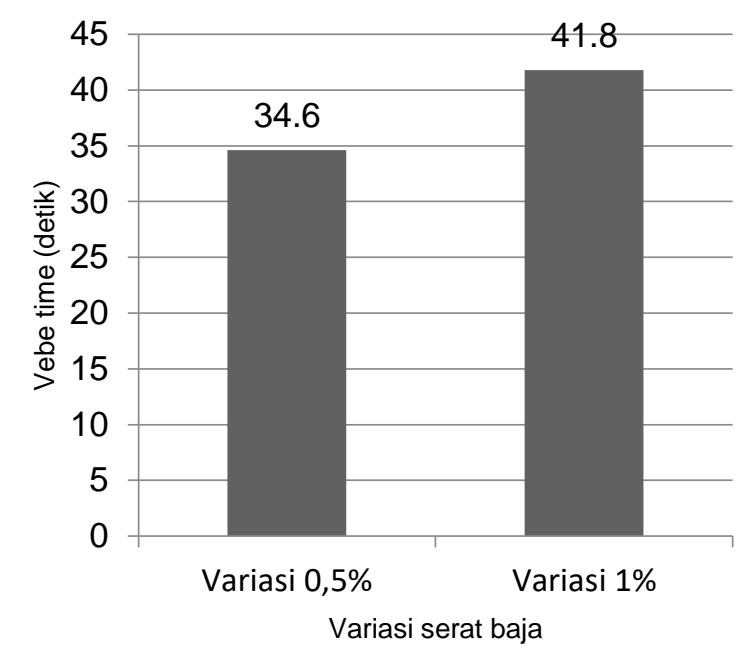

Gambar 5. Hubungan variasi serat baja dengan vebe time test

Pengujian vebe time menunjukkan bahwa campuran RCC yang dibuat mempunyai kelecakan rendah (beton normal berkisar antara 15 - 30 detik). Hasil pengujian vebe time memperlihatkan lembab gembur (sedikit kering). Semakin banyak penambahan serat baja membuat nilai vebe time semakin besar sehingga workability menurun. Kondisi ini sesuai dengan pernyataan Sudarmoko (1993) bahwa serat baja menambah ikatan antar agregat pada campuran beton sehingga memperlambat keruntuhan adukan beton dalam silinder alat vebe time. 

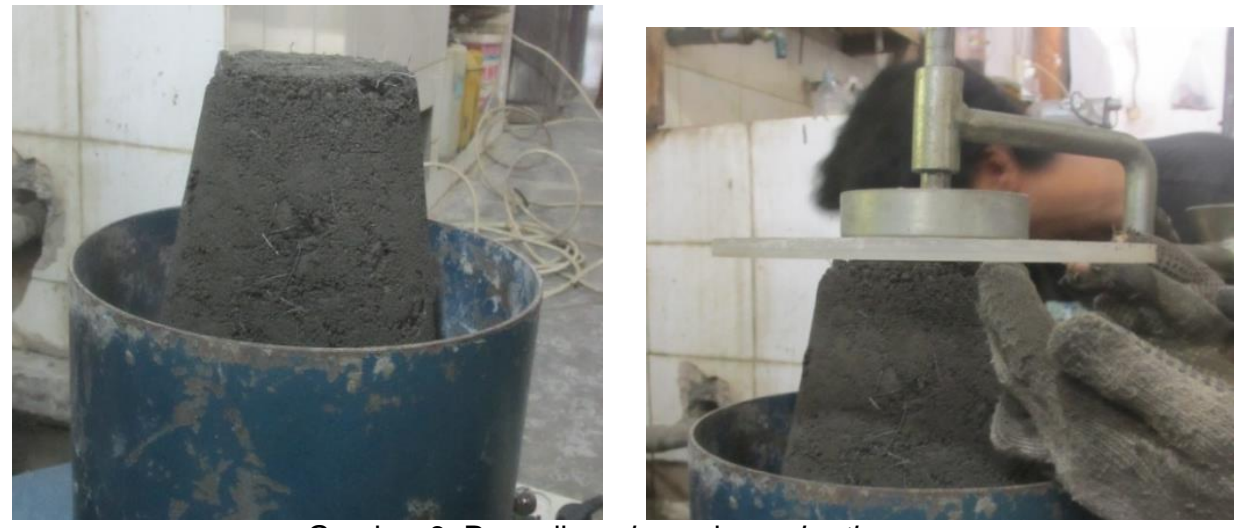

Gambar 6. Pengujian slump dan vebe time

Benda uji mempunyai berat volume ratarata untuk variasi serat $0,5 \%$ dapat dilihat pada Tabel 4, sedangkan untuk variasi serat $1 \%$ dapat dilihat di bawah ini.

Tabel 6. Berat volume beton variasi serat $0,5 \%$

\begin{tabular}{ccccc}
\hline Kode & Volume $\left(\mathrm{cm}^{3}\right)$ & Berat $(\mathrm{kg})$ & Berat Volume $\left(\mathrm{kg} / \mathrm{m}^{3}\right)$ & Rata-Rata $\left(\mathrm{kg} / \mathrm{m}^{3}\right)$ \\
\hline B1-1 $0,5 \%$ & 13.923 & 32,50 & 2.334 & \\
B2-1 0,5\% & 13.829 & 31,80 & 2.300 & 2.329 \\
B3-1 0,5\% & 13.802 & 31,80 & 2.304 & \\
B1-28 0,5\% & 13.910 & 32,80 & 2.358 & \\
B2-28 0,5\% & 13.690 & 32,30 & 2.359 & \\
B3-28 0,5\% & 13.899 & 32,20 & 2.317 & \\
\hline
\end{tabular}

Tabel 7. Berat volume beton variasi serat $1 \%$

\begin{tabular}{ccccc}
\hline Kode & Volume $\left(\mathrm{cm}^{3}\right)$ & Berat $(\mathrm{kg})$ & Berat Volume $\left(\mathrm{kg} / \mathrm{m}^{3}\right)$ & Rata-Rata $\left(\mathrm{kg} / \mathrm{m}^{3}\right)$ \\
\hline B1-1 1\% & 13.798 & 32,20 & 2.334 & 2.299 \\
B2-1 1\% & 13.835 & 31,80 & 2.342 & 2.308 \\
B3-1 1\% & 13.747 & 32,20 & 2.279 & \\
B1-28 1\% & 13.865 & 31,60 & 2.304 & \\
B2-28 1\% & 13.759 & 31,70 & 2.288 & \\
B3-28 1\% & 13.983 & 32,00 & \\
\hline
\end{tabular}

Pengujian umur beton 1 hari dilakukan untuk mengetahui kekuatan beton 1 hari karena RCC dirancang untuk menerima beban lalu lintas secepat mungkin. Hasil uji kekuatan beton 1 hari digunakan untuk perhitungan kemampuan perkerasan kaku menerima beban lalu lintas hari pertama.

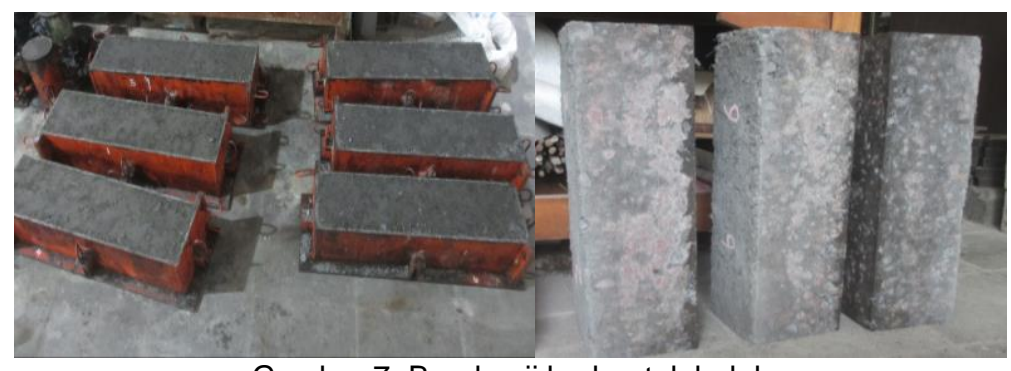

Gambar 7. Benda uji berbentuk balok

Hasil pengujian diperoleh kuat lentur untuk umur beton 1 hari sebesar 4,2 $\mathrm{MPa}$ sedangkan umur beton 28 hari sebesar 5,7 MPa. Hasil uji kuat lentur umur 1 hari dengan 
umur 28 hari mengalami peningkatan sebesar 1,5 MPa. Hasil uji kuat lentur umur beton 1 hari sebesar 3,4 MPa sedangkan umur beton 28 hari sebesar $6,1 \mathrm{MPa}$. Selisih kuat lentur umur 1 hari dengan 28 hari sebesar 2,7 $\mathrm{MPa}$.

Tabel 8. Hasil pengujian kuat lentur

\begin{tabular}{cccc}
\hline No & Variasi & Umur 1 Hari (MPa) & Umur 28 Hari (MPa) \\
\hline 1. & Variasi 0,5\% & 4,2 & 5,7 \\
2. & Variasi 1\% & 3,4 & 6,1 \\
\hline
\end{tabular}

Perbandingan kuat lentur variasi $0,5 \%$ dengan $1 \%$ dapat dilihat pada Gambar 5 .

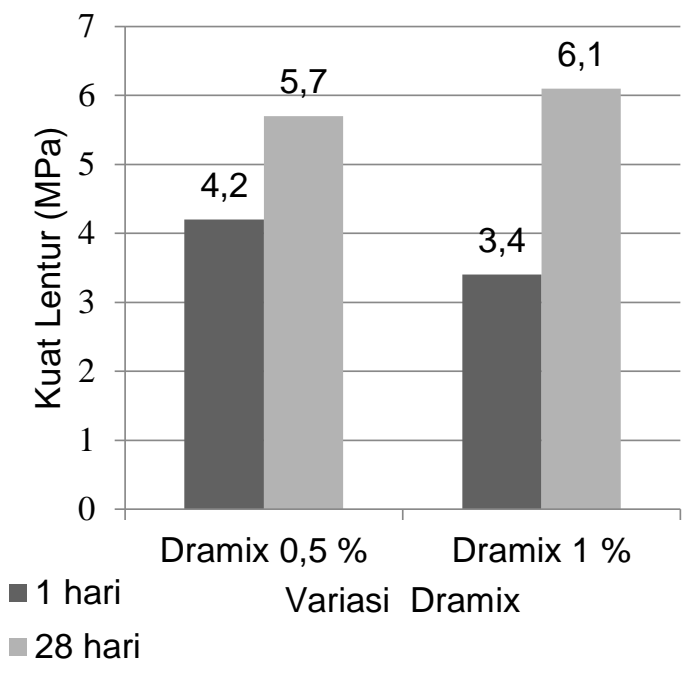

Gambar 8. Hubungan variasi dramix dengan kuat lentur.

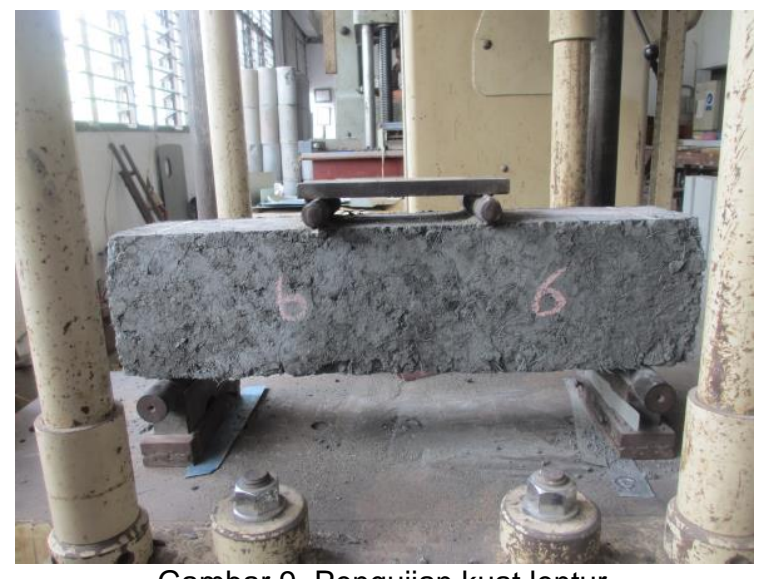

Gambar 9. Pengujian kuat lentur

Kecenderungan penambahan serat baja meningkatkan kuat lentur pada beton umur 28 hari. Pengujian kuat lentur ini membuktikan bahwa serat baja efektif menahan tarik pada beton sehingga meningkatkan kuat lenturnya. Serat baja juga mampu menahan terjadinya keruntuhan secara tiba-tiba sehingga jika mengalami kelebihan beban maka akan mengalami kehancuran secara perlahan. Kondisi ini 
sesuai dengan pendapat Sudarmoko (1993) yang menyatakan bahwa secara teoritis benda uji tidak akan terjadi lendutan sebelum benda uji mengalami keruntuhan. Keruntuhan total benda uji terjadi segera setelah retak pertama muncul, sedangkan pada pengujian balok beton serat terjadi keruntuhan secara perlahan dengan diawali suatu retak kecil yang semakin lama bertambah besar.

Serat baja bekerja lebih efektif apabila posisi tegak lurus dengan gaya yang bekerja karena lebih kuat menahan gaya tarik daripada gaya tekan. Posisi serat baja dalam campuran beton tidak dapat diatur karena proses pencampuran membuat posisi serat baja menjadi acak atau tidak teratur. Posisi serat baja diasumsikan menyebar dengan posisi yang bervariasi. Jumlah serat pada retakan mempengaruhi kekuatan beton, semakin banyak jumlah serat pada retakan akan semakin kuat menahan lentur. Kondisi serat baja yang menggumpal mungkin terjadi apabila kadar serat baja lebih banyak. Semakin besar komposisi serat baja semakin besar kemungkinan serat baja menggumpal pada satu bagian beton. Kondisi ini sesuai dengan peningkatan aspek rasio yang tinggi akan menyebabkan serat cenderung untuk menggumpal menjadi suatu bola (balling effect) yang sangat sulit disebar secara merata sebelum dan sesudah pengadukan.

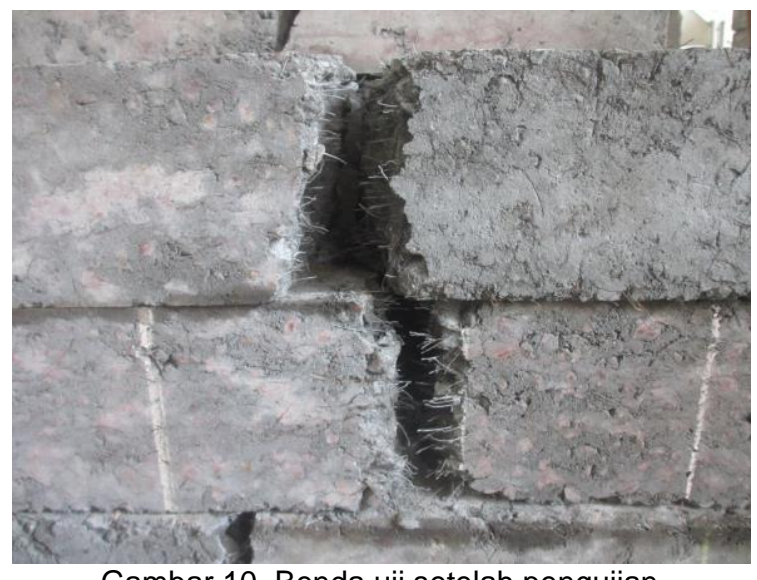

Gambar 10. Benda uji setelah pengujian

Penggunaan faktor air semen yang sangat rendah memungkinkan berkurangnya rekatan antar agregat dan serat dengan adukan semen. Campuran beton yang terlalu kering akan mempengaruhi proses hidrasi semen dalam campuran. Kondisi retakan benda uji menunjukan bahwa ikatan antara serat baja dengan campuran beton

\section{SIMPULAN}

Hasil kajian pada Roller compacted concrete $(R C C)$ mengenai kuat lentur beton dengan bahan tambah serat baja (dramix) sesuai variasi diperoleh kesimpulan antara lain:

1. Hasil pengujian kuat lentur RCC pada umur 1 hari dan 28 hari untuk variasi serat baja (dramix) 0,5\% diperoleh 4,2 $\mathrm{MPa}$ dan 5,7 MPa sedangkan untuk belum melebihi kekuatan tarik serat baja. Kondisi ini terlihat pada serat yang hanya terlepas dari campuran beton (tidak putus). Percobaan variasi faktor air semen dapat dilakukan untuk mencari kebutuhan air paling optimum sehingga menghasilkan rekatan antara serat baja dengan campuran beton menjadi maksimal. variasi serat baja (dramix) $1 \%$ diperoleh 3,4 MPa dan 6,1 MPa.

2. Penambahan serat baja semakin banyak mampu menambah kakuatan beton terhadap lentur pada umur beton 28 hari. 
Pengujian campuran beton RCC pada umur 1 hari telah menghasilkan kuat lentur yang tinggi.

\section{DAFTAR RUJUKAN}

ACl 207.5R-99, 2004. Roller Compacted Mass Concrete. In $\mathrm{ACl}$ manual of concrete practice. USA. p.47.

Badan Standarisasi Nasional, SNI 03-28342000. Tata Cara Pembuatan Rencana Campuran Beton Normal. Jakarta.

Badan Standarisasi Nasional, SNI 19742011. Cara Uji Kuat tekan Beton Dengan Benda Uji Silinder. Jakarta.

Badan Standarisasi Nasional, SNI 44312011. Cara Uji Kuat Lentur Beton Normal Dengan Dua Titik Pembebanan. Jakarta.

Briggs, A., Bowen, D.H. \& Kollek, J., 1974. Mechanical Properties and Durability of Fibre Reinforced Cement Composite. In Proceeding Of International Conference Carbon Fibres. London, 1974. The Plastic Institute.

Dipohusodo, I., 1994. Struktur Beton Bertulang. Jakarta: PT. Gramedia Pustaka Utama.

Direktorat Jenderal Bina Marga, 2006. Manual Konstruksi dan Bangunan: Buku 5 Lapis Pondasi Beton Padat Giling (BPG/RCC). Jakarta.

Muzamil \& Budiono, 1994. Pengaruh Pemakaian Bahan Tambah Super Plasticizer Terhadap Kuat Desak
Beton. Tugas Akhir Strata 1. Yogyakarta: Universitas Islam Indonesia.

Pratama, G. N. I. P., \& Sumarjo, H. (2018). Aksesibilitas Tata Letak Elevator Penumpang Gedung Kantor Pusat Layanan Terpadu (KPLT) Fakultas Teknik UNY. INformasi dan Ekspose hasil Riset Teknik Slpil dan Arsitektur, 14(1), 26-35.

Prihadi, W. R., \& Pratama, G. N. I. P. (2016). Konfigurasi Batang Pada Perancangan Rangka Atap Bambu. INformasi dan Ekspose hasil Riset Teknik Slpil dan Arsitektur, 12(2), 173-183.

Tjokrodimuljo, K., 2012. Teknologi Beton. Yogyakarta: KMTS FT UGM.

Saragi, Y.R.R., 2014. Tinjauan Perkerasan Beton (Rigid Pavement) dengan RCC (Roller Compacted Concrete). Jurnal Teknik Mommensen, 1.

Sudarmoko, 1993. Indeks Tahanan Lentur Beton Serat. Forum Teknik, Jilid 17, pp.57-65.

Zai, K.A., Syahrizal \& Karolina, R., 2014. Pengaruh Penambahan Silica Fume dan Superplasticizer Terhadap Kuat Tekan Beton Mutu Tinggi Dengan Metode ACl (American Concrete Institute). Jurnal Teknik Sipil USU, Vol. 3 No. 2. 